\title{
Trabalho, abuso de drogas e os aparelhos ideológicos de Estado: um estudo com alunos do ensino médio e fundamental
}

\author{
| ${ }^{1}$ Martial de Magalhães Câmara, ${ }^{2}$ Anamaria Testa Tambellini, \\ ${ }^{3}$ Amadeu Roselli-Cruz |
}

Resumo: A pesquisa se baseia em trabalho de prevenção de dependência entre estudantes de 23 municípios de quatro regiōes brasileiras. Foram analisados 68.210 questionários referentes a Região Norte (29.386 questionários / 7 cidades), Região Nordeste (17.971 questionários / 3 cidades), Região Sudeste (4.197 questionários / 4 cidades) e Região Sul (16.656 questionários / 9 cidades). Os questionários continham 25 perguntas, das quais oito foram estudadas. Encontraramse respostas aproximadas em todas as regiões brasileiras. Observou-se ainda que não foi possível estabelecer uma relação entre o trabalho e a experiência de abuso de drogas. A Igreja e a escola se mostraram extremamente importantes na formação dos jovens. A escola se mostrou herdeira de um trabalho educativo antes restrito às famílias. O abuso de drogas foi encontrado, na Região Norte, em torno de $2 \%$, sendo na Região Nordeste em torno de 6\%, na Região Sudeste e Sul em cerca de 5\%. A idade predominante para o primeiro uso se situou entre 11 e 15 anos em todas as regiōes estudadas e o percentual maior foi de alunos do ensino fundamental. Encontrouse alguma concordância com o trabalho de Althusser, no que se refere aos aparelhos ideológicos de Estado. A Igreja e a família tiveram uma importância muito grande para a busca de apoio ou esclarecimentos por parte desses jovens.

> Palavras-chave: drogas; trabalho; adolescentes; escolares; vício; Epidemiologia; Saúde Coletiva.

\author{
${ }^{1}$ Psicanalista, Mestre em Saúde \\ Coletiva pela Universidade \\ Federal do Rio de Janeiro \\ e Pesquisador do Centro \\ de Estudos de Drogas da \\ Universidade Santa Úrsula \\ (CEDUSU). Endereço eletrônico: \\ martial.camara@hotmail.com \\ 2 Professora Adjunta do \\ Instituto de Estudos em \\ Saúde Coletiva e Faculdade \\ de Medicina da Universidade \\ Federal do Rio de Janeiro. \\ ${ }^{3}$ Professor Adjunto da \\ Faculdade de Medicina da \\ Universidade Federal de Minas \\ Gerais. Diretor Científico do \\ Centro de Estudos de Drogas da \\ Universidade Santa Úrsula.
}

Recebido em: 13/05/2009. Aprovado em: 19/10/2009. 
A finalidade deste trabalho é refletir sobre pesquisa realizada com 68.210 estudantes que responderam a questionário usado nas primeiras fases de programa de prevenção à dependência. Estudamos as variáveis: trabalho de jovens, escolaridade, idade do primeiro abuso, família, religião e relações sociais outras.

Droga, segundo seu termo correlato grego (Phármakon), é uma palavra ambígua que expressa tanto o veneno, quanto o medicamento que cura ou salva. O falar geral, entretanto associou o significado de substância entorpecente, alucinógena ou excitante (ROSELLI-CRUZ, 1992). As drogas acompanham a Humanidade desde seu alvorecer. Seu uso e abuso constituem problemas muito antigos na história do homem.

A ciência farmacológica só começou a se firmar no século XIX, mas o uso lenitivo já vinha ocorrendo há muito tempo, através de erros e acertos. Os povos primitivos desenvolveram controles sociais eficientes para tal uso. $\mathrm{O}$ primeiro produto encontrado deve ter sido o álcool, provavelmente após a ação de alguma levedura trazida pelo vento até uma porção de restos de frutas. Os egípcios fabricavam uma bebida fermentada de nome "trag" (ANDRADE, 1992). Dois dos principais textos da cultura ocidental: a Bíblia e a Odisseia,trazem relato de consumo de vinho e pó, provavelmente de extração vegetal misturado a vinho.

$\mathrm{O}$ aparecimento da civilização e a consequente tomada de consciência do destino, da finitude humana, fizeram com que uma angústia vital, nem sempre aliviada pelas religióes, tomasse conta da mente e coraçôes dos homens. A descoberta da função ansiolítica do álcool propiciou o nascimento desse elo dependência-abuso. Com a Revolução Industrial, o desenvolvimento das técnicas de produção que causaram a diminuição do preço dos produtos (MARX, 1867/1985), os trabalhadores, recebendo salários, puderam ter acesso às bebidas. $\mathrm{O}$ acréscimo de consumidores, além do trabalho da mulher e do menor, propiciaram o terreno ideal para que a dependência química passasse a desempenhar papel cada vez mais forte.

As grandes guerras trouxeram um acréscimo do abuso químico, após a disseminação do uso de substâncias para aliviar a dor, opiáceos, e para dar energia, anfetaminas (ANDRADE, 1992). Houve um incremento do interesse na prevenção da dependência química e verificamos que o foco de atenção deve estar dirigido para a pessoa que esteja em situação de fragilidade social, entre as quais, os jovens. 
Há vários significados para o termo "dependência", mas este compreende um sujeito frente a algo ou outro sujeito, sem o qual imagina não ter possibilidade de prazer ou até mesmo possibilidade de existir. Mais recentemente, a dependência pode também ser vista como uma prática psicótica e suicida, com fantasias de desprender-se do corpo e iludir o "outro", que acaba sendo percebido como perseguidor (KALINA, 1999).

Quando se pensa em dependência, pensa-se também na falta de liberdade exemplificada pela dificuldade em ocupar os espaços potenciais de desenvolvimento (ROSELLI-CRUZ, 1992). Verifica-se atualmente uma dificuldade na implantação de limites na família. A família moderna sofre uma mudança com a diminuição do poder parental e a incapacidade de esses pais de estabelecerem limites necessários para o desenvolvimento das novas gerações (TIBA, 1996).

\section{Métodos}

Realizou-se estudo descritivo transversal, no qual foram analisadas as proporções do abuso de drogas lícitas e ilícitas e sua associação com as variáveis: aquisição da primeira droga, o trabalho, a importância da escola, família e religião. Foi desenvolvido em um programa de prevenção do Centro de Estudos de Drogas da Universidade Santa Úrsula (CEDUSU), que contou com a participação de prefeituras, clubes de serviços e organizações não-governamentais. Este suporte teve como objetivo alcançar um número expressivo de escolas, jovens, professores, famílias, empresas e seus funcionários, grupos religiosos e policiais. O trabalho de pesquisa é resultado de dissertação de mestrado apresentada ao IESC/UFRJ.

$\mathrm{O}$ instrumento utilizado foi um questionário respondido por alunos das cidades onde o programa foi implantado. Destes, escolhemos 68.210, respondidos entre os anos de 2000 a 2003. As principais variáveis incluíam abuso de drogas, trabalho de menores, escolaridade, religião e família, entre outras. O questionário autoaplicado foi respondido anonimamente, com o consentimento por escrito dos responsáveis na família e na escola.

A necessidade do questionário, anônimo e autoaplicado, foi conhecer a realidade local. O CEDUSU não utiliza um modelo pronto de trabalho, mas estuda essa realidade para ajudar a equipe local a trabalhar. $\mathrm{O}$ objetivo é estimular, na comunidade, uma cultura de prevenção calcada em valores sociais dos grupos, procurando respostas dentro do repertório de atitudes de cada grupo. O CEDUSU 
somente atua numa comunidade se convidado por ela, não se oferecendo através de intermediários ou pela mídia. As atividades foram iniciadas no Paraná e a partir daí fomos chamados para outros estados.

Uma vez respondidos, os questionários foram devolvidos para digitação dos dados, elaboração de tabelas e gráficos e análise estatística dos mesmos, através de testes para comparação de proporções (Teste do Qui-Quadrado Yates Corrected). Tal trabalho foi feito em programa desenvolvido na Universidade Santa Úrsula e baseado no programa EPI INFO 6.0, distribuído gratuitamente pelo Center on Diseases Control, Atlanta, Geórgia USA.

A população estudada foi de crianças e adolescentes que participaram das fases iniciais dos programas de formação de equipes de multiplicação em quatro regiōes nacionais durante os anos de 2000 a 2003. A partir da análise dos questionários pela equipe central, foram iniciadas as fases de treinamento e aperfeiçoamento. A finalidade principal com relação aos professores é trabalhar a dependência com os alunos dentro de sua disciplina, sem sair do seu conteúdo programático. Entre os resultados obtidos, escolhemos sete municípios na Região Norte, três municípios na Região Nordeste, quatro na Região Sudeste e nove municípios na Região Sul.

A pesquisa obedeceu aos padrões éticos estabelecidos pela Resolução no 196/96 do Conselho Nacional de Saúde; o projeto foi aprovado pelo Conselho Científico do CEDUSU e realizado com a permissão das Secretarias de Educação estadual e municipal. O inquérito epidemiológico é de uso exclusivo da equipe de pesquisa e os pesquisadores garantem que nenhum estranho à equipe terá acesso aos dados, para que se preserve a confidencialidade. Não obstante, a divulgação dos resultados da pesquisa deve ser pública e em primeiro lugar endereçada aos sujeitos da pesquisa.

\section{Resultados}

$\mathrm{Na}$ tabela 1, encontraram-se $52,05 \%$ de alunas para $45,95 \%$ de alunos, predominância do sexo feminino que se observa na população estudantil nacional, conforme o Censo Demográfico de 2000. A Região Nordeste apresentou uma relação mais equilibrada na variável sexo; o fato de o estudo ter sido feito em capitais e numa cidade da grande Fortaleza deve ter contribuído para tal resultado. Na Região Sudeste, observou-se predomínio de alunas, com exceção de Alegre. O mesmo se verificou na Região Sul, com duas cidades, Parobé e Três Coroas, onde os alunos predominaram por pequena margem. $\mathrm{O}$ 
índice de alunos que não responderam ao quesito foi semelhante nas regiões

Sul e Norte: menor que $1 \%$. Esse índice foi maior nas regióes Nordeste e Sudeste, $4,10 \%$ e $6,81 \%$, respectivamente.

Tabela 1: Distribuição de questionários válidos por sexo segundo regióes e municípios estudados/ Brasil 2000 a 2003

\begin{tabular}{|c|c|c|c|c|}
\hline Regiāo / Município & Sexo Masculino & Sexo Feminino & Sexo Ignorado & Total \\
\hline \multicolumn{5}{|l|}{ REG. NORTE } \\
\hline Ariquemes (RO) & $1.555(39.79 \%)$ & $2.352(60.17 \%)$ & $2(0.05 \%)$ & 3.909 \\
\hline Cacoal (RO) & $1.687(46.92 \%)$ & $1.875(52.14 \%)$ & $34(0.94 \%)$ & 3.596 \\
\hline Guajará Mirim (RO) & $1.041(44.74 \%)$ & $1.278(54.92 \%)$ & $8(0.34 \%)$ & 2.327 \\
\hline Ji-Paraná (RO) & $2.441(45.10 \%)$ & $2.940(54.31 \%)$ & $32(0.59 \%)$ & 5.413 \\
\hline Porto Velho (RO) & $3.350(43.88 \%)$ & $4.206(55.10 \%)$ & $78(1.02 \%)$ & 7.634 \\
\hline Rolim de Moura (RO) & $1.055(38.36 \%)$ & $1.683(61.20 \%)$ & $12(0.44 \%)$ & 2.750 \\
\hline Vilhena (RO) & $1.772(47.17 \%)$ & $1.965(52.30 \%)$ & $20(0.53 \%)$ & 3.757 \\
\hline Sub Total & $12.901(43.90 \%)$ & $16.299(55.47 \%)$ & $186(0.63 \%)$ & $29386(43.09 \%)$ \\
\hline \multicolumn{5}{|l|}{ REG. NORDESTE } \\
\hline Caucaia (CE) & $318(46.90 \%)$ & $360(53.10 \%)$ & $0(0 \%)$ & 678 \\
\hline Fortaleza (CE) & $5.099(49.94 \%)$ & $4.294(42.82 \%)$ & $726(7.24 \%)$ & 10.029 \\
\hline Natal (RN) & $3.304(45.48 \%)$ & $3.948(54.35 \%)$ & $12(0.17 \%)$ & 7.264 \\
\hline Sub total & $8.631(48.03 \%)$ & $8.602(47.87 \%)$ & $738(4,10 \%)$ & $17.971(26.34 \%)$ \\
\hline \multicolumn{5}{|l|}{ REG. SUDESTE } \\
\hline Alegre (ES) & $532(51.20 \%)$ & $465(44.76 \%)$ & $42(4.04 \%)$ & 1039 \\
\hline Itabira $(\mathrm{MG})$ & $480(44.04 \%)$ & $596(54.68 \%)$ & $14(1.28 \%)$ & 1090 \\
\hline Nova Lima (MG) & $611(40.84 \%)$ & $655(43.78 \%)$ & $230(15,38 \%)$ & 1.496 \\
\hline Raposos (MG) & $260(45.45 \%)$ & $312(54.55 \%)$ & $0(0 \%)$ & 572 \\
\hline Sub Total & $1.883(44.87 \%)$ & $2.028(48.32 \%)$ & $286(6.81 \%)$ & $4.197(6.15 \%)$ \\
\hline \multicolumn{5}{|l|}{ REG. SUL } \\
\hline Araucária (PR) & $752(47.09 \%)$ & $807(50.53 \%)$ & $38(2.38 \%)$ & 1.597 \\
\hline Canela (RS) & $1.523(45.15 \%)$ & $1.805(53.51 \%)$ & $45(1.34 \%)$ & 3.373 \\
\hline Gramado (RS) & $693(46.76 \%)$ & $775(52.29 \%)$ & $14(0.95 \%)$ & 1.482 \\
\hline Igrejinha (RS) & $575(47.44 \%)$ & $637(52.56 \%)$ & $0 \quad(0 \%)$ & 1.212 \\
\hline Osório (RS) & $385(48.43 \%)$ & $410(51.57 \%)$ & $0(0 \%)$ & 795 \\
\hline Parobé (RS) & $1.232(50.00 \%)$ & $1.210(49.11 \%)$ & $22(0.89 \%)$ & 2.464 \\
\hline Pato branco (PR) & $648(45.76 \%)$ & $767(54.17 \%)$ & $1(0.07 \%)$ & 1.416 \\
\hline Taquara (RS) & $1.112(48,77 \%)$ & $1.161(50.92 \%)$ & $7(0.31 \%)$ & 2.280 \\
\hline Três Coroas (RS) & $1.006(49.38 \%)$ & $1.004(49.29 \%)$ & $27(1.33 \%)$ & 2.037 \\
\hline Sub total & $7.926(47.59 \%)$ & $8.576(51.49 \%)$ & $154(0.92 \%)$ & $16.656(24.42 \%)$ \\
\hline TOTAL & $31.341(45.95 \%)$ & $35.505(52.05 \%)$ & $1.364(2.00 \%)$ & 68.210 \\
\hline
\end{tabular}

Proporção sexo masculino/feminino da Região Nordeste em comparação ao total do Brasil: QuiQuadrado Yates Corrected $=56,08$ e P valor $=0,00000$ 
Na tabela 2, o total dos estudantes pesquisados, comparados com a população estudantil local, segundo o Censo Demográfico 2000, ficou em 8,32\%. Essa relação foi maior na Região Sul, especialmente nas cidades de Três Coroas e Canela. Número próximo foi observado na Região Norte. A Região Nordeste apresentou relação menor e a Região Sudeste apresentou resultados mais próximos à média nacional.

Tabela 2: Relação aproximada entre os questionários válidos em cada município e a população estudantil de acordo com o censo demográfico. Brasil-2000.

\begin{tabular}{|c|c|c|c|}
\hline Região / Município & Questionários válidos & População Estudantil & Percentagem \\
\hline \multicolumn{4}{|l|}{ REG. NORTE } \\
\hline Ariquemes (RO) & 3.909 & 6.921 & 56.48 \\
\hline Cacoal (RO) & 3.596 & 7.581 & 47.43 \\
\hline Guajará Mirim (RO) & 2.327 & 4.153 & 56.03 \\
\hline Ji-Paraná (RO) & 5.413 & 11.973 & 45.21 \\
\hline Porto Velho (RO) & 7.634 & 60.778 & 12.56 \\
\hline Rolin de Moura (RO) & 2.750 & 3.532 & 77.85 \\
\hline Vilhena (RO) & 3.757 & 6.766 & 55.52 \\
\hline Subtotal & 29.386 & 101704 & 28.89 \\
\hline \multicolumn{4}{|l|}{ REG. NORDESTE } \\
\hline Caucaia $(\mathrm{CE})$ & 678 & 25.117 & 2.69 \\
\hline Fortaleza $(\mathrm{CE})$ & 10.029 & 440.016 & 2.27 \\
\hline Natal (RN) & 7.264 & 163.320 & 4.44 \\
\hline Subtotal & 17.971 & 628.453 & 2.85 \\
\hline \multicolumn{4}{|l|}{ REG. SUDESTE } \\
\hline Alegre (ES) & 1.039 & 5.021 & 20.69 \\
\hline Itabira (MG) & 1.090 & 15.708 & 6.93 \\
\hline Nova Lima (MG) & 1.496 & 12.149 & 12.31 \\
\hline Raposos (MG) & 572 & 1.166 & 49.05 \\
\hline Subtotal & 4.197 & 34.044 & 12.32 \\
\hline \multicolumn{4}{|l|}{ REG. SUL } \\
\hline Araucária (PR) & 1.597 & 10.870 & 14.69 \\
\hline Canela (RS) & 3.373 & 4.744 & 71.10 \\
\hline Gramado (RS) & 1.482 & 4.347 & 34.09 \\
\hline Igrejinha (RS) & 1.212 & 2.651 & 45.71 \\
\hline Osório (RS) & 795 & 6.089 & 13.05 \\
\hline Parobé (RS) & 2.464 & 3.625 & 67.97 \\
\hline Pato Branco (PR) & 1.416 & 12.548 & 11.28 \\
\hline Taquara (RS) & 2.280 & 7.619 & 29.92 \\
\hline Três Coroas (RS) & 2.037 & 2.514 & 81.02 \\
\hline Subtotal & 16.656 & 55.007 & 30.27 \\
\hline TOTAL & 68.210 & 819.208 & $8.32 \%$ \\
\hline
\end{tabular}

Proporção de alunos pesquisados em relação à população registrada no Censo Escolar da Região Norte, em comparação ao total do Brasil: Qui-Quadrado Yates Corrected $=28602,92$ e P valor $=0,00000$ 
Na tabela 3, verifica-se que entre a população estudantil pesquisada, prevaleceram os estudantes do curso fundamental (71\%), ficando os alunos do ensino médio com a proporção de $26 \%$. Não responderam a esse quesito $3 \%$ do total. O maior índice para o ensino médio foi encontrado na Região Norte e o menor, na Região Nordeste. Quanto ao resultado da pergunta sobre o trabalho paralelo aos estudos, 28\% de alunos disseram "sim", contra $67 \%$ que referiram não o fazer. Não responderam à questão 5\% do total. As regiōes Norte e Sul apresentaram resultados semelhantes.

$\mathrm{Na}$ tabela 4, no total nacional, declararam ter feito uso de droga alguma vez na vida em torno de $4 \%$ da população pesquisada. Destes, na Região Norte $2 \%$ declararam ter feito uso de drogas, na Região Nordeste foi encontrado o maior índice, em torno de 7\%. Nas regiōes Sul e Sudeste, o índice foi igualmente 6\%. $\mathrm{Na}$ Região Norte, encontrou-se um alto número de quesitos não respondidos.

$\mathrm{Na}$ tabela 5, com referência à idade do primeiro uso de droga, encontrou-se a faixa dos 11 a 15 anos para $49 \%$ dos entrevistados no total nacional, contra $23 \%$ acima dos 15 anos. As regiōes Nordeste, Sudeste e Sul tiveram percentual semelhante, em torno de 54\%. A Região Norte apresentou percentual de 43\% para essa faixa de idade, mas apresentou também um número expressivo de nãorespostas, em torno de $35 \%$.

Tabela 3: Distribuição das variáveis escolaridade e trabalho da população estudantil estudada segundo regióes. Brasil, 2000 a 2003.

\begin{tabular}{|l|c|c|c|c|c|}
\hline \multicolumn{5}{|c|}{ REGIÔES } \\
\hline Escolaridade & Norte & Nordeste & Sudeste & Sul & TOTAL \\
\hline Ens. Médio & $9.698(33 \%)$ & $3.414(19 \%)$ & $1.259(30 \%)$ & $3.498(21 \%)$ & $17.869(26 \%)$ \\
\hline Fundamental & $18.219(62 \%)$ & $13.838(77 \%)$ & $2.770(66 \%)$ & $12.992(78 \%)$ & $47.819(71 \%)$ \\
\hline Não respondeu & $1.469(5 \%)$ & $719(4 \%)$ & $168(4 \%)$ & $166(1 \%)$ & $2.522(3 \%)$ \\
\hline Trabalho & $9.110(31 \%)$ & $3.774(21 \%)$ & $1.091(26 \%)$ & $5.330(32 \%)$ & $19.305(28 \%)$ \\
\hline Trabalha & $16.750(57 \%)$ & $13.658(76 \%)$ & $2.938(70 \%)$ & $10.993(66 \%)$ & $44.339(67 \%)$ \\
\hline Não trabalha & $3.526(12 \%)$ & $539(3 \%)$ & $168(4 \%)$ & $333(2 \%)$ & $4.566(5 \%)$ \\
\hline Não respondeu & $3.96)$ &
\end{tabular}

Distribuição da escolaridade de população estudantil estudada segundo regiões. Qui-Quadrado Yates Corrected $=506,22$ e P valor $=0,00000$

Proporção alunos que declaram ou não trabalhar da Região Nordeste em relação ao total Nacional: Qui-Quadrado Yates Corrected $=506,22$ e P valor = 0,00000 
Tabela 4: Distribuição do uso de drogas entre os estudantes pesquisados, segundo as regióes e municípios. 2000 a 2003

\begin{tabular}{|c|c|c|c|}
\hline Região / Município & Sim & Não & Não respondeu \\
\hline \multicolumn{4}{|l|}{ REGIÃO NORTE } \\
\hline Ariquemes (RO) & $78(2 \%)$ & $1.837(47 \%)$ & $1.994(51 \%)$ \\
\hline Cacoal (RO) & $36(1 \%)$ & $1.762(49 \%)$ & $1.798(50 \%)$ \\
\hline Guajará-Mirim (RO) & $47(2 \%)$ & $1.094(47 \%)$ & $1.186(51 \%)$ \\
\hline Ji-Paraná (RO) & $54(1 \%)$ & $2.977(55 \%)$ & $2.382(44 \%)$ \\
\hline Porto Velho (RO) & $153(2 \%)$ & $3.893(51 \%)$ & $3.588(47 \%)$ \\
\hline Rolin de Moura (RO) & $28(1 \%)$ & $1.320(48 \%)$ & $1.402(51 \%)$ \\
\hline Vilhena (RO) & $113(3 \%)$ & $1.803(48 \%)$ & $1.841(49 \%)$ \\
\hline Subtotal & $509(2 \%)$ & $14.686(50 \%)$ & $14191(48 \%)$ \\
\hline \multicolumn{4}{|c|}{ REGIÃO NORDESTE } \\
\hline Caucaia (CE) & $34(5 \%)$ & $624(92 \%)$ & $20(3 \%)$ \\
\hline Fortaleza (CE) & $702(7 \%)$ & $9.227(92 \%)$ & $100(1 \%)$ \\
\hline Natal (RN) & $436(6 \%)$ & $6.537(90 \%)$ & $291(4 \%)$ \\
\hline Subtotal & $1.172(7 \%)$ & $16.388(91 \%)$ & $411(2 \%)$ \\
\hline \multicolumn{4}{|l|}{ REGIÃO SUDESTE } \\
\hline Alegre (ES) & $94(9 \%)$ & $914(88 \%)$ & $31(3 \%)$ \\
\hline Itabira (MG) & $66(6 \%)$ & $1.024(94 \%)$ & - \\
\hline Nova Lima (MG) & $60(4 \%)$ & $1.421(95 \%)$ & $15(1 \%)$ \\
\hline Raposos (MG) & $28(5 \%)$ & $538(94 \%)$ & $6(1 \%)$ \\
\hline Subtotal & $248(6 \%)$ & $3.897(93 \%)$ & $52(1 \%)$ \\
\hline \multicolumn{4}{|l|}{ REGIÃO SUL } \\
\hline Araucária (PR) & $128(8 \%)$ & $1.469(92 \%)$ & - \\
\hline Canela (RS) & $135(4 \%)$ & $3.204(95 \%)$ & $34(1 \%)$ \\
\hline Gramado (RS) & $89(6 \%)$ & $1.363(92 \%)$ & $30(2 \%)$ \\
\hline Igrejinha (RS) & $61(5 \%)$ & $1.139(94 \%)$ & $12(1 \%)$ \\
\hline Osório (RS) & $48(6 \%)$ & $739(93 \%)$ & $8(1 \%)$ \\
\hline Parobé (RS) & $148(6 \%)$ & $2.242(91 \%)$ & $74(3 \%)$ \\
\hline Pato Branco (PR) & $113(8 \%)$ & $1.303(92 \%)$ & - \\
\hline Taquara (RS) & $228(10 \%)$ & $1.984(87 \%)$ & $68(3 \%)$ \\
\hline Três Coroas (RS) & $102(5 \%)$ & $1.915(94 \%)$ & $20(1 \%)$ \\
\hline Subtotal & $1.052(6 \%)$ & $15.358(93 \%)$ & $246(1 \%)$ \\
\hline TOTAL & $2.981(4 \%)$ & $50.329(74 \%)$ & $14.900(22 \%)$ \\
\hline
\end{tabular}

Proporção de consumo de drogas da Região Norte em comparação ao total do Brasil: Qui-Quadrado Yates Corrected $=122,47$ e P valor $=0,00000$ 
Tabela 5: Distribuição da idade, em anos, do primeiro abuso de droga entre os estudantes pequisados segundo as regióes e municípios. 2000 a 2003

\begin{tabular}{|c|c|c|c|}
\hline Região / Município & 11 a 15 anos & Acima de 15 anos & Não responderam \\
\hline \multicolumn{4}{|l|}{ REGIÃO NORTE } \\
\hline Ariquemes (RO) & $25(33 \%)$ & $23(29 \%)$ & $30(38 \%)$ \\
\hline Cacoal (RO) & $13(36 \%)$ & $3(7 \%)$ & $20(57 \%)$ \\
\hline Guajará Mirim（RO） & $21(45 \%)$ & $18(38 \%)$ & $8(17 \%)$ \\
\hline Ji- Paraná (RO) & $19(35 \%)$ & $9(17 \%)$ & $26(48 \%)$ \\
\hline Porto Velho (RO) & $72(47 \%)$ & $40(26 \%)$ & $41(27 \%)$ \\
\hline Rolin de Moura (RO) & $14(50 \%)$ & $4(15 \%)$ & $10(35 \%)$ \\
\hline Vilhena (RO) & $58(52 \%)$ & $25(22 \%)$ & $30(26 \%)$ \\
\hline Subtotal & $222(43 \%)$ & $122(22 \%)$ & $165(35 \%)$ \\
\hline \multicolumn{4}{|l|}{ REGIÃO NORDESTE } \\
\hline Caucaia (CE) & $18(52 \%)$ & $5(15 \%)$ & $11(33 \%)$ \\
\hline Fortaleza (CE) & $408(58 \%)$ & $161(23 \%)$ & $133(19 \%)$ \\
\hline Natal (RN) & $214(49 \%)$ & $126(29 \%)$ & $96(22 \%)$ \\
\hline Subtotal & $640(54 \%)$ & $292(25 \%)$ & $240(21 \%)$ \\
\hline \multicolumn{4}{|l|}{ REGIÃO SUDESTE } \\
\hline Alegre (ES) & $46(48 \%)$ & $24(26 \%)$ & $24(26 \%)$ \\
\hline Itabira (MG) & $39(59 \%)$ & $18(27 \%)$ & $9(14 \%)$ \\
\hline Nova Lima (MG) & $34(57 \%)$ & $16(27 \%)$ & $10(16 \%)$ \\
\hline Raposos (MG) & $12(43 \%)$ & $11(40 \%)$ & $5(17 \%)$ \\
\hline Subtotal & $131(53 \%)$ & $69(29 \%)$ & $48(18 \%)$ \\
\hline \multicolumn{4}{|l|}{ REGIÃO SUL } \\
\hline Araucária (PR) & $69(54 \%)$ & $25(20 \%)$ & $34(26 \%)$ \\
\hline Canela (RS) & $66(49 \%)$ & $24(18 \%)$ & $45(33 \%)$ \\
\hline Gramado (RS) & $49(55 \%)$ & $21(24 \%)$ & $19(21 \%)$ \\
\hline Igrejinha (RS) & $32(53 \%)$ & $15(24 \%)$ & $14(23 \%)$ \\
\hline Osório (RS) & $28(59 \%)$ & $9(20 \%)$ & $11(21 \%)$ \\
\hline Parobé (RS) & $78(53 \%)$ & $26(18 \%)$ & $44(29 \%)$ \\
\hline Pato Branco (PR) & $59(52 \%)$ & $24(21 \%)$ & $30(27 \%)$ \\
\hline Taquara (RS) & $139(61 \%)$ & $57(25 \%)$ & $32(14 \%)$ \\
\hline Três Coroas (RS) & $50(49 \%)$ & $18(18 \%)$ & $34(33 \%)$ \\
\hline Subtotal & $570(54 \%)$ & $219(21 \%)$ & $263(25 \%)$ \\
\hline TOTAL & $1.563(49 \%)$ & $702(23 \%)$ & $716(28 \%)$ \\
\hline
\end{tabular}

Proporção questionários não respondidos da Região Norte em comparação ao total do Brasil: Qui-Quadrado Yates Corrected $=8,95$ e P valor $=0,00277$ 
Analisando-se a tabela 6, observa-se, do total nacional, que a família foi escolhida para busca de ajuda para evitar as drogas em 29\%. A escola ficou logo após, com 19\%, seguida da Igreja, com 16\%. O médico teve um papel razoável, com $14 \%$ de indicações. As regiōes Sul e Sudeste tiveram percentuais semelhantes entre si, com aumento das indicações para a Igreja e diminuição para o médico. A escola manteve os números nacionais. Na Região Nordeste, houve aumento dos resultados da escola, Igreja e família e diminuição dos demais, em relação ao total nacional. Na Região Norte, encontrou-se um aumento significativo de respostas para a importância do médico com diminuição para família, Igreja e escola. Do número total nacional, verificou-se que para a busca de esclarecimento sobre drogas, a escola obteve $32 \%$, resultado semelhante em todas as regiōes pesquisadas. A família ficou com $22 \%$, número também encontrado nas quatro regiôes. A mídia teve 19\%, estando à frente da Igreja. Esta só apresentou percentual maior na Região Norte: 18\% contra 13\% do total nacional.

Tabela 6: Caracterização da busca de ajuda e esclarecimentos para evitar o abuso de drogas, segundo possibilidades sugeridas. Brasil, 2000 a 2003

\begin{tabular}{|l|c|c|c|c|c|}
\hline & \multicolumn{5}{|c|}{ REGIŌES } \\
\hline & Norte & Nordeste & Sudeste & Sul & TOTAL \\
\hline Busca de Esclarecimentos & $3.428(12 \%)$ & $4.007(22 \%)$ & $702(17 \%)$ & $2.638(16 \%)$ & $10.775(16 \%)$ \\
\hline Escola & $4.478(15 \%)$ & $4.101(23 \%)$ & $1.064(25 \%)$ & $3.668(22 \%)$ & $13.311(19 \%)$ \\
\hline Igreja & $5.421(18 \%)$ & $6.564(36 \%)$ & $1.432(34 \%)$ & $6.136(37 \%)$ & $19.553(29 \%)$ \\
\hline Família & $5.789(20 \%)$ & $1.384(8 \%)$ & $414(10 \%)$ & $1.750(10 \%)$ & $9.337(14 \%)$ \\
\hline Médico & $4.203(14 \%)$ & $751(4 \%)$ & $167(4 \%)$ & $828(5 \%)$ & $5.949(9 \%)$ \\
\hline Polícia & $4.993(17 \%)$ & $274(2 \%)$ & $113(3 \%)$ & $361(2 \%)$ & $5.741(8 \%)$ \\
\hline Outros & $1.074(4 \%)$ & $890(5 \%)$ & $305(7 \%)$ & $1.275(8 \%)$ & $3.544(5 \%)$ \\
\hline Não informou & & & & \\
\hline Busca de Ajuda & $9.493(33 \%)$ & $5.902(33 \%)$ & $1.247(30 \%)$ & $5.128(31 \%)$ & $21.770(32 \%)$ \\
\hline Escola & $5.373(18 \%)$ & $1.897(11 \%)$ & $316(7 \%)$ & $1.512(9 \%)$ & $9.098(13 \%)$ \\
\hline Igreja & $5.920(20 \%)$ & $4.445(25 \%)$ & $876(21 \%)$ & $3.812(23 \%)$ & $15.053(22 \%)$ \\
\hline Família & $5.021(17 \%)$ & $3.425(19 \%)$ & $971(23 \%)$ & $3.123(19 \%)$ & $12.540(19 \%)$ \\
\hline Mídia & $2.092(7 \%)$ & $1.171(6 \%)$ & $464(11 \%)$ & $1.866(11 \%)$ & $5.593(8 \%)$ \\
\hline Polícia & $561(2 \%)$ & $864(5 \%)$ & $195(5 \%)$ & $966(6 \%)$ & $2.586(4 \%)$ \\
\hline Outros & $926(3 \%)$ & $267(1 \%)$ & $128(3 \%)$ & $249(1 \%)$ & $1.570(2 \%)$ \\
\hline Não informou & & & & \\
\hline
\end{tabular}




\section{Discussão e conclusões}

Lidamos com os conceitos de trabalho, educação e adolescência, esta última como uma fase de um necessário confronto, sem retaliação, com uma pessoa adulta que aceita esse desafio. É também uma fase de crise de identidade, com o uso de linguagem própria, especial. Essa crise de identidade pode-se mostrar mais aguçada na fase final, podendo levar a quadro de adolescência prolongada, incompleta, com adaptações neuróticas (BLOS, 1985).

A força de trabalho jovem aumentou nos anos 1970, não só nas cidades, em desencontro com a lei regulamentadora (BRASIL, 1997). A legislação é insuficientemente aplicada em nosso país. De maneira geral, os jovens gostam de trabalhar, isto lhes dá uma identidade social através do labor (TIBA, 1996). A necessidade de entrar no mercado de trabalho é prioritária para os menores, mas estes o fazem sem uma formação melhor. Ocorre entrada de grupo muito considerável de menores no mercado sem experiências para lidar com os novos paradigmas desse mercado do trabalho, que a moderna tecnologia modificou (SOUZA et al., 1999), além dos riscos do adoecimento nos jovens com trabalhos desqualificados (PINHEIRO, 1999). Os indicadores existentes, especialmente os de mortalidade e letalidade, evidenciam que as condições de trabalho no Brasil e o padrão de saúde dessas pessoas que trabalham são preocupantes (TAMBELLINI; CAMARA, 1998). Apesar da necessidade familiar do produto do trabalho dos menores, estes geralmente recebem salários entre as faixas mais baixas. A partir dos anos 80 , os jovens passaram a ser atraídos para a ilegalidade, com participação cada vez maior no tráfico de drogas (ATHAYDE, 2006; BARCELOS, 2005).

As escolas, por seu lado, não prestam muita atenção às diferenças individuais dos alunos, gerando dificuldades, sobretudo naqueles mais vulneráveis, social e economicamente, e este é um dos aspectos que este trabalho encontrou em todas as regiões pesquisadas, em número razoável. A ação da escola cresceu em importância, com a ida da mulher para o mercado de trabalho e com a passagem da família para a escola, das tarefas educacionais quase que totais. Como o melhor sinônimo para prevenção é educação, essa tarefa passou a ser um parâmetro novo nos objetivos escolares (ROSELI-CRUZ, 1992).

Um dos fatores moduladores de consumo de drogas é a religião (DALGALARRONDO, 2004). As várias dimensōes da religiosidade relacionam-se com o abuso de drogas por efeito inibidor do consumo. Por outro lado, uma família 
desestruturada tem influência negativa. Com o início da dependência química, em geral prepondera o abuso de álcool e fumo, vindo depois a maconha associada a outras drogas. Nas classes mais altas, prevalece o álcool (BLAUS, 2002).

Com a crise adolescente, normal nessa faixa etária, os jovens se tornam o ponto de inserção das drogas na vida humana, fase na qual começa de maneira geral a dependência química. Entre as várias causas que atuam nesse período, podemos citar: a curiosidade normal do jovem; a pressão do grupo; a ideia de imortalidade; a necessidade da adoção de uma linguagem comum; a solidariedade intragrupal (ROSELLI-CRUZ, 1992). Com o início do abuso químico, aparecem sinais de que a família e a escola podem usar como parâmetro a queda do rendimento escolar e o aumento da evasão (LARANJEIRA, 1999). O ponto de partida não é necessariamente o ambiente universitário, mas os cursos fundamental e médio (FIORINI et al., 2003), com maior ênfase no fundamental.

Observa-se maior presença de estudantes do sexo feminino no universo pesquisado. Historicamente, a média nacional por sexo dos alunos matriculados apresenta predomínio do sexo feminino (IBGE, 2003). Há predomínio de mulheres na população nacional e pode-se imaginar que as necessidades econômicas e sociais obrigam a entrada dos meninos no mercado de trabalho mais cedo.

$\mathrm{Na}$ Região Sul, há um número mais elevado de alunos que declararam trabalhar. Como se trata de uma região geográfica nacional com melhor situação econômica e cultural, o esperado seria um número maior de crianças com suporte para estudar sem necessidade de ir para o mercado de trabalho. Na Região Nordeste o patamar foi mais baixo, e pode-se pensar em mercado de trabalho com menor oferta, face ao sul do país.

Prevaleceu em todas as regióes estudadas o maior número de alunos do curso fundamental sobre o curso médio, com participação maior do ensino médio na Região Sul. O apoio incansável dos clubes de serviço locais e das secretarias de educação pode explicar essa amostragem.

Quanto ao quesito do uso de drogas, encontraram-se percentuais semelhantes a outros estudos (GALDUROZ, 1997). O quantitativo não respondido neste quesito foi muito maior na Região Norte. É possível que um interesse muito grande por parte das autoridades locais tenha influenciado.

Quanto à idade do primeiro uso, em todo o país observou-se o predomínio de idade inferior a 15 anos. Isso desloca o problema da experiência de drogas 
para o ensino fundamental, confirmando os achados e as preocupações do

CEDUSU de incluir as primeiras séries no trabalho preventivo. Muitos jovens deixaram a questão em branco. Podemos pensar em receio de quebra do sigilo com autoridades educativas locais, ou num viés de memória.

Não obstante as mudanças sociais ocorridas no mundo desde os anos 1960, a família, a Igreja e a escola se mostraram importantes na criação ou no reforço de fatores de resistência, à dependência química. Conforme se pode ver nos resultados, para os jovens de hoje, essas instituições continuam tendo papéis seminais. A pesquisa, a preparação, a consecução e a manutenção de um programa de reabilitação devem levar em conta essas instituições. De maneira geral, quase toda comunicação se dirige ao pessoal, ao indivíduo isoladamente, porém a ação preventiva só poderá ser eficaz quando levar em conta o conjunto Estado, sociedade civil, família, escola e religião.

$\mathrm{Na}$ década de 70, estudou-se a importância dos aparelhos ideológicos de Estado (AIE). Esses seriam certo número de realidades que se apresentariam ao observador sob a forma de instituições distintas e especializadas, haveria o AIE religioso, AIE escolar, o AIE familiar, ao lado de aparelhos mais comuns, o jurídico, político, sindical, da informação, cultural e assim por diante. Os AIE seriam motivo de resistência às mudanças sociais e os mais importantes seriam aqueles sem estatuto público. Pode-se imaginar que as resistências se fazem valer no tocante à proteção de uma comunidade face à mudança do padrão de dependência, de diminuição da liberdade pessoal e do estreitamento das possibilidades que o abuso químico traz (ALTHUSSER, 1970).

O AIE religioso teve seu papel diminuído a partir da Revolução Industrial, mas ainda tem sua importância e um percentual importante de jovens busca apoio na religião. O AIE escolar desempenha incontestavelmente um papel dominante nos tempos modernos. Este AIE recebe crianças de todas as classes sociais e inculca, durante anos em que a criança está vulnerável, saberes práticos e morais.

Como características psicológicas importantes, pensamos na identificação, a primeira forma de relação objetal (FREUD, 1923). Essa identificação incluiria fatores de proteção inconscientemente, a partir do ego dos pais. A autoestima, como fator de maturação do ego da criança, está relacionada ao ser amado pelo superego, substituto intrapsíquico dos pais. O superego, por seu lado, seria também uma extensão psíquica da cultura, que se inseriria na estrutura do ego 
com características semelhantes àquelas biológicas do id, por serem impressas de maneira definitiva (ANDRADE, 1993). Poder-se-ia presumir a existência de uma herança cultural perpetuada através do superego por mecanismo de identificação, na esfera da afetividade. A psicanálise nos mostrou a importância da repressão (FREUD 1946), necessária para a vida civilizada, mas responsável por alteraçôes psíquicas quando em excesso (FREUD, 1929). O homem precisa da força que o grupo social lhe dá; para isso, precisa desistir de alguns prazeres pessoais, passíveis de postergação, para o bem comum do grupo.

Todas as características psicológicas citadas são remetidas à criação por parte do Homem, de um projeto de vida, projeto esse que não deixa espaços vazios que podem ser ocupados pela dependência.

\section{Referências}

ALTHUSSER, L. Ideologia e Aparelhos Ideológicos de Estado. Lisboa: Editorial Presença, 1970. $120 \mathrm{p}$.

ANDRADE, O. M. Aids e uso de drogas. In: ROSELLI-CRUZ, A. (Org.). Educação e prevenção do abuso de drogas. Rio de Janeiro: Editora Universitária Santa Úrsula. 1992. p. 117-126.

ANDRADE, V. M. Psicanálise de amplo espectro. Rio de Janeiro: Imago, 1993. 163 p.

ATHAYDE, C.; BILL, M. V. Falcão: meninos do tráfico. Rio de Janeiro: Objetiva, 2006. $251 \mathrm{p}$.

BARCELlOS, C. Abusado: o dono do morro Dona Marta. Rio de Janeiro. Record, 2005. $559 \mathrm{p}$.

BLAUS, J.; KUPEK, E.; PIRES, M. Prevalence and risk factors associated with drug use among school students. Brazil. Revista Saúde Pública. São Paulo, v. 36, n. 1, p. 40-46, 2002.

BLOS, P. Adolescência: uma interpretação psicanalítica. São Paulo: Martins Fontes, 1985. $260 \mathrm{p}$.

BRASIL. Ministério do Trabalho. Cartilha do Trabalhador Adolescente. Rio de Janeiro. Delegacia Regional do Trabalho no Estado do Rio de Janeiro. 1997. 172 p.

DALGALARRONDO, P.; SOLDERA, M. A.; CORREIA-FILHO, H. R. Religion and drug-use by adolescents. Rev. Bras. Psiquiatria, Rio de Janeiro, v. 26, n. 2, p. 82-90, 2004.

FIORINI, J.E.; ALVES, A. L.; FERREIRA, L. R. Use of licit and illicit drugs at the University of Alfenas. Rev Hosp Clin, São Paulo, v. 58, n. 4, p. 199-206, 2003. 
FREUD, A. O ego e os mecanismos de defesa. Rio de Janeiro: Civilização Brasileira, 1974. $149 \mathrm{p}$.

FREUD, S. O ego e o id. In: . Coleção Completa das Obras Psicológicas. v XIX. Rio de Janeiro: Imago, 1974. p. 12-83.

FREUD, S. O mal-estar na civilização. In: . Coleção Completa das Obras Psicológicas. v XXI. Rio de Janeiro: Imago, 1974. p. 75-171.

GALDURÓZ, J. C. F. Levantamento sobre o uso de drogas entre estudantes de primeiro e segundo graus em dez capitais brasileiras. São Paulo: EDUSP-CEBRID, 1997. 130 p.

INSTITUTO BRASILEIRO DE GEOGRAFIA E ESTATÍSTICA. Censo Demográfico 2000. Rio de Janeiro: Fundação IBGE, 2003. 219 p.

KALINA, E. Et al. Drogadição hoje: indivíduo família e sociedade. Porto Alegre: Artes Médicas Sul, 1999. 232 p.

LARANJEIRA, R. et al. Orientação familiar para dependentes químicos: perfil, expectativas e estratégias. J Bras Psiq, Rio de Janeiro, v. 48, n. 10, p. 471-478, 1999.

MARX, K. O Capital. V. 1. São Paulo: Nova Cultural, 1985. 301 p.

PINHEIRO, A. B. O trabalho precoce em adolescentes matriculados em escolas municipais da Zona Sul do Rio de Janeiro. 1999. 175 p. Tese (Doutorado em Saúde Pública) - Escola de Saúde Pública, Fundação Oswaldo Cruz, Rio de Janeiro, 1999.

ROSELLI-CRUZ, A. Prevenção do abuso de drogas pela educação formal. In: ROSELLICRUZ, A. (Org.). Educação e prevenção do abuso de drogas. Rio de Janeiro: Editora Universitária Santa Úrsula, 1992. p. 29-44.

SOUZA, D.P.O. et al. Confiabilidade de variáveis selecionadas para um instrumento sobre o uso de drogas entre estudantes adolescente trabalhadores e não trabalhadores da rede estadual de ensino de Cuiabá, Mato Grosso, Brasil. Rio de Janeiro. Cad Saúde Colet., v. 7, n. 1, p. 89, 1999.

TAMBELlini, A. T.; CAMARA, V. M. A temática saúde e ambiente no processo de desenvolvimento do campo de Saúde Coletiva: aspectos históricos, conceituais e metodológicos. Ciência e Saúde Coletiva, v. 3, n. 2, 1998.

TIBA, I. Disciplina: O Limite na Medida Certa. São Paulo. Editora Gente, 1996. 193p. 


\section{Abstract}

Work, drug addiction and apparatus of state:

a study with students of elementary and secondary school

The research was based on a drug abuse prevent program among 68,210 students in Brazil. Questionnaires were applied in four Brazilian Regions: North ( $\mathrm{n}=29,386$ in 7 cities); Northeast ( $\mathrm{n}=17,971$ in 3 cities); Southeast ( $\mathrm{n}$ $=4,197$ in 4 cities) and South ( $\mathrm{n}=16,656$ in 9 cities). This questionnaire included 25 questions and among then, eight were studied. Similar answers were found in all regions of the country. The main conclusions were: religion and school were pointed as an extreme importance as an educational aspect in the children's own lives. School replaced an educational role, that was a former family privilege. The experience of drug abuse in childhood was measured in: North (2\%), Northeast $(6 \%)$, South and Southeast (5\%). The prevailing age of the first drug use was found between 11 and 15 years old in all the regions, during the fundamental school degree. Certain agreement with Althuser's work on ideological apparatus of State was found. Family and religion were important protection factors against drug abuse.

> Key words: drugs; addiction; work; adolescence; school, public health; epidemiology. 